\title{
Aplicação da metodologia DMAIC para redução dos desperdícios em uma indústria de gesso do interior de Pernambuco, Brasil
}

\author{
Application of the DMAIC methodology to reduce waste in a gypsum industry in \\ the interior of Pernambuco, Brazil
}

\author{
Ciro Henrique de Araújo Fernandes \\ https://orcid.org/0000-0002-7788-9659 \\ Ana Cristina Gonçalves Castro Silva \\ https://orcid.org/0000-0001-8682-7794 \\ Andréa de Vasconcelos Ferraz \\ https://orcid.org/0000-0001-8043-1414 \\ Pedro Vieira Souza Santos \\ https://orcid.org/0000-0001-9802-506X
}

\begin{abstract}
Mestre em Engenharia de Produção. Universidade Federal do Vale do São Francisco (UNIVASF) - Brasil. ciro.fernandes@aol.com. Doutora em Engenharia Industrial. Universidade Federal do Vale do São Francisco (UNIVASF) - Brasil. castroanasilva@gmail.com Doutora em Ciência dos Materiais. Universidade Federal do Vale do São Francisco (UNIVASF) - Brasil. andrea.ferraz@univasf.edu.br Mestre em Engenharia de Produção. Universidade Federal do Vale do São Francisco (UNIVASF) - Brasil. pedrovieirass@hotmail.com
\end{abstract}

\section{RESUMO}

A metodologia DMAIC é uma forte aliada para melhoria da qualidade tanto na produção quanto no produto. No sentido de melhorar a qualidade do produto da empresa e diminuir os desperdícios na produção, este trabalho teve como objetivo principal sugerir ações em uma empresa produtora de gesso localizada na cidade de Trindade-PE. Através da metodologia DMAIC, e suas ferramentas da qualidade, buscou-se encontrar causas raízes para os principais problemas que afetam a produção de gesso e levam aos desperdícios. Foi observado que se as 47,06 toneladas de rejeito, 23,53 (50\%) fossem vendidas como gesso de revestimento por $\mathrm{R} \$ 236,50$ a tonelada, elas representariam um aumento de pelo menos $\mathrm{R} \$ 5.564,85$ no faturamento de gesso de revestimento em um período de 3 meses. Na etapa Analisar, foram realizadas entrevistas com os colaboradores, diretores e gestores da empresa para criação dos gráficos de ISHIKAWA com o objetivo de levantar as possíveis causas que levam ao desperdício na produção. Construiu-se matrizes de Causa e Efeito para avaliação das causas potenciais e, em seguida foi feita a análise de causa raiz, para as sete causas destacadas no ranking resultante. Foram elaborados os planos de ação - 5W1H, onde foram propostas diversas medidas para melhorar o ambiente de trabalho e diminuir os desperdícios no setor produtivo. Notou-se, portanto, que as causas organizacionais foram as que apresentaram maior correlação, o que foi entendido que as causas organizacionais em ordem de prioridade, devem ser as primeiras a serem combatidas.

Palavras-chave: produção de gesso; calcinação; metodologia DMAIC; qualidade.

\begin{abstract}
The DMAIC methodology is a strong ally for quality improvement in both, the production and in the product itself. In order to improve the quality of a company product and reduce waste in production, this work had as main objective to suggest actions in a gypsum-producing industry located in the city of Trindade-PE. Through the DMAIC methodology, and its quality tools, we sought to find root causes for the main problems that affect gypsum production and lead to waste. It was observed that if the 47.06 tons of tailings, 23.53 (50\%) were sold as gypsum lining for $\mathrm{R} \$ 236.50$ a ton, they would represent an increase of at least $\mathrm{R} \$ 5,564.85$ in sales of gypsum coating over a period of 3 months. In the Analyze phase of the research, interviews were conducted with the employees, directors and managers of the company to create ISHIKAWA graphics in order to detect the possible causes that lead to waste in production. Cause and Effect matrices were constructed to assess potential causes, and then root cause analysis was performed for the seven causes highlighted in the resulting ranking. Action plans were drawn up - 5W1H, where several measures were proposed to improve the work environment and reduce waste in the production sector. It was noted that the organizational causes were the ones that showed the greatest correlation, which means that, in order of priority, they should be the first to be tackled to solve the problem raised.
\end{abstract}

Keywords: gypsum production; calcination; DMAIC methodology; quality. 


\section{INTRODUÇÃO}

A região pernambucana produtora de gesso, mais conhecida como Polo Gesseiro do Araripe (PGA), surgiu por volta da década de 60 com as atividades de mineração de Gipsita. O PGA abrange os Municípios de Araripina, Bodocó, Exú, Ipubí, Ouricuri e Trindade, que representam 8,69\% do território do Estado e 2,98\% da população pernambucana (SHINOHARA; OLIVEIRA, 2014; SANTOS et al., 2019). Nesse contexto, as organizações da cadeia produtiva gesseira têm uma preocupação em comum: redução de custos, o que, em curto prazo, pode não ser a melhor estratégia, pois, com o passar do tempo, esses custos voltam e acabam tornando-se um círculo vicioso (LEE; COVELL, 2008; MACHADO; CIPRIANO et al., 2019; SANTOS, 2020).

Como consequência, a qualidade vem tornando-se um fator crucial para a sobrevivência das empresas, sobretudo em ambientes altamente competitivos, isso reforça a necessidade de buscar alternativas de longo prazo que ajudem a aprimorar os processos e os produtos alcançando um nível de desempenho cada vez mais eficiente para se manterem competitivas e atenderem às expectativas de um mercado dinâmico e de clientes cada vez mais exigentes (SILVA; MACHADO, 2011; BARBOSA et al., 2019 SANTOS, 2019; SANTOS FILHO et al., 2020).

A falta de controle e planejamento de ações na produção pode gerar inúmeros prejuízos, dificultando a permanência dessas empresas no mercado. Qualquer instituição que queira se manter atuando com qualidade no mercado deve adaptar-se às mudanças, buscar e implementar novos conceitos no ambiente interno e desenvolver estratégias para alcançar o sucesso (KRÜGER, 2013; SANTOS, 2020).

A gestão da qualidade é uma das principais estratégias competitivas adotadas nas empresas e em diversos setores, sendo utilizadas ferramentas para controlar a produção, possibilitando a melhoria de produtos e serviços, visando garantir a completa satisfação das necessidades dos clientes. Segundo Peinado e Graeml (2007), a qualidade implica na busca contínua da satisfação dos clientes, conseguindo atender as suas expectativas, sejam eles internos ou externos à organização. Os fatores qualidade e produtividade, são relevantes na perpetuidade da organização e de seus produtos e serviços, e tem como relação direta a redução dos custos, identificação e diminuição de perdas nos processos, e, aumento da competitividade e atenção às necessidades dos clientes.

A ferramenta de gestão da qualidade, Seis Sigma, é uma iniciativa que vem ao encontro das necessidades de melhorias de uma organização oferecendo benefícios para o processo produtivo, ambiente de trabalho e de retorno financeiro (Santos, 2018). Segundo Montgomery e Woodall (2008), a metodologia Seis Sigma, que é uma abordagem disciplinada, é fundamentada em dados estatísticos, que orienta projetos a fim de reduzir variabilidade, remover defeitos e eliminar desperdícios de produtos, processos e serviços.

Mahanti e Antony (2009) identificaram que a aplicação do Seis Sigma tem tornado possível que as empresas, além de produzirem com maior qualidade, melhorem a performance dos produtos, obtenham maior produtividade, reduzam custos e aumentem a satisfação dos clientes. A sua aplicabilidade fica melhor estabelecida com a metodologia DMAIC, cujas siglas significam: Define (Definir), Measure (Medir) e Analyse (Analisar). A metodologia DMAIC norteia a sequência do trabalho e o uso correto das ferramentas da qualidade em cada etapa. Esse ciclo pode ser utilizado de forma independente, mas sua aplicação é muito frequente em ferramentas de excelência operacional e em projetos Seis Sigma. Segundo Mandal (2012), a ferramenta Seis Sigma deve focar nos processos e a metodologia DMAIC tem as cinco fases interdependentes.

Segundo Campos (2014), o DMAIC baseia-se no ciclo original do PDCA (Planeje - Execute - Verifique Ações Corretivas), que é um método que auxilia na prática do controle e que se constitui a base da melhoria. O DMAIC tem cinco passos padronizados: definir, medir, analisar, melhorar e controlar (KUAN, 2012). A metodologia DMAIC é utilizada para melhorar processos existentes e tem provado sua eficácia na redução de custos, tempo de ciclo, e aumentando a satisfação do cliente, além de aumentar a lucratividade em muitas indústrias e organizações (PRASHAR, 2014).

Nesse sentido, a região do Araripe tem muitas indústrias produtoras de gesso que geram muitos empregos e desenvolvem a região onde se encontram, contudo, sua representatividade está sendo afetada pelo atual cenário do mercado brasileiro que vem passando por uma grave crise econômica nos últimos dois anos. Por exemplo, muitas organizações daquela região não contam com sistemas de gerenciamento e 
acompanhamento da produção, mas sim com uma estrutura simples de planejamento, muitas vezes deficiente.

Levando em consideração o exposto, observa-se a necessidade e oportunidade de aproveitar as ferramentas de gestão da qualidade para que os processos dentro das indústrias do Araripe sejam controlados e otimizados, abrangendo aspectos como: eliminação dos desperdícios, definição das necessidades dos clientes e a variabilidade na produção. As empresas que não têm eficiência em seus processos produtivos, raramente conseguem manter-se estáveis no mercado (MACEDO, 2012; SANTOS; SILVA, 2019; SANTOS et al., 2020).

Os desperdícios também são considerados eventos que trazem prejuízos significativos ao desempenho operacional. De acordo com Bornia (2010), os custos dos desperdícios abrangem todos os insumos consumidos nas empresas de forma não eficiente e não eficaz, abrangendo inclusive as atividades desenvolvidas repetitivamente para a correção de problemas na produção bem como no desenvolvimento de atividades desnecessárias na empresa. Os desperdícios são consequências que geram gastos de tempo e dinheiro, adicionando custos desnecessários aos produtos manufaturados das empresas, conforme apontam Santos e Clemente (2019).

Liker e Meier (2007) citam que o caminho da busca pela melhoria de produtividade se divide em dois: o primeiro, em que se procuram e analisam os desperdícios do processo e se utilizam ferramentas de qualidade para a sua solução; e o segundo, em que se procura melhorar o que já existe (Kaizen), podendo ser a disponibilidade de equipamentos, o seu desempenho ou o índice de qualidade, melhorias estas localizadas, mas que podem influenciar no processo como um todo.

Considerando a dimensão do impacto produzido por problemas relacionados às variabilidades, aos desperdícios e ao controle dos processos produtivos de uma indústria, pode-se estudar: quais sugestões de melhorias podem ser propostas com a aplicação da metodologia DMAIC para aperfeiçoamento da qualidade, proporcionando redução de desperdícios e aumentando a qualidade nos produtos e processos da indústria do gesso. Isto posto, o objetivo do presente trabalho foi aplicar as etapas: Define (Definir), Measure (Medir) e Analyse (Analisar) da metodologia DMAIC, em uma indústria de gesso, localizada no Polo Gesseiro do Araripe, na cidade de Trindade-PE.

\section{REFERENCIAL TEÓRICO}

Nesta seção serão apresentados alguns conceitos atrelados à temática analisada, tais como: a produção de gesso e seu processo, além de aspectos em gestão da qualidade e da metodologia DMAIC.

\subsection{Processo produtivo do gesso}

A gipsita é o mineral utilizado para a obtenção do gesso. Essa rocha sedimentar é constituída basicamente de sulfato de cálcio di-hidratado ( $\mathrm{CaSO} 4.2 \mathrm{H} 2 \mathrm{O}$ ). O Brasil possui reservas significativas de gipsitas distribuídas pela região Norte, Nordeste ou Centro-Oeste, fato que o posiciona como o $11^{\circ}$ produtor mundial e torna possível suprir todo o consumo interno. As jazidas que apresentam melhores condições de aproveitamento econômico e consideradas como maiores depósitos lavráveis estão contidas na Bacia Sedimentar do Araripe, na divisa dos estados de Pernambuco, Ceará e Piauí (SINDUSGESSO, 2017).

O gesso é um material encontrado em várias regiões do mundo e suas técnicas de produção fazem parte de uma longa tradição que integram as formas de fabricação, as condições locais, as fontes naturais, e os hábitos de utilização. Segundo Lima Filho (2010), o minério de gipsita da região do Araripe é considerado o de melhor qualidade no mundo, apresentando um teor de pureza entre $88 \%$ e $98 \%$.

A matriz energética da indústria do gesso no Araripe é bem diversificada, sendo formada por energia elétrica, derivados de petróleo e biomassa, principalmente lenha. A eletricidade se encontra presente em todas as etapas, porém, contribui com apenas $3 \%$ do total energético. A lenha é o principal elemento utilizado na matriz energética desse setor. O coque é o segundo energético mais utilizado com $10 \%$, seguido do óleo BPF 
(Baixo Poder de Fluidez) com 8\%, utilizados na calcinação. O diesel contribui com $5 \%$ do consumo sendo utilizado na mineração e uma parcela muito restrita utilizada nas calcinadoras.

O segmento gesseiro possui uma cadeia produtiva própria e o beneficiamento da gipsita para a produção de gesso por desidratação térmica envolve as seguintes operações básicas: (1) britagem; (2) rebritagem; (3) peneiramento (usado apenas em algumas empresas); (4) encilhamento; (5) calcinação; (6) estabilização térmica em silos; (7) moagem (de acordo com as especificações de mercado para o produto); (8) encilhamento e (9) ensacamento (PERES; BENACHOUR; SANTOS, 2008).

De acordo com Perez et al. (2008), a calcinação (principal etapa do processo) da gipsita é realizada com a liberação de água de cristalização ou água de combinação contida na gipsita e que normalmente ocorre numa faixa de temperatura compreendida entre $105^{\circ} \mathrm{C}-150^{\circ} \mathrm{C}$. Contudo, a reação de desidratação com obtenção de hemidrato é encontrada em patamares de temperaturas contidas no intervalo de aproximadamente $175^{\circ} \mathrm{C}$ a $250^{\circ} \mathrm{C}$, onde pode ser encontrada anidrita solúvel, denominada de gesso rápido.

\subsection{Gestão da Qualidade}

Devido às constantes mudanças econômicas, as empresas precisam adotar sistemas de gestão para melhorar seus processos produtivos reduzindo custos e adequando-se às novas realidades. A dinâmica envolvente a nível externo implica em competitividade, inovação e na capacidade de adaptar-se às mudanças repentinas do mercado mantendo o nível da produtividade (JONES; LINDERMAN, 2014).

O conceito de qualidade envolve muitas interpretações, devido a sua particularidade da interpretação e significado. Segundo Paladini (2008), para o conceito de qualidade, o primeiro passo é considerar como um conjunto de atributos ou elementos que compõe o produto ou serviço da empresa. Em complemento Silva Junior (2013), a gestão da qualidade tem como objetivo atender aos requisitos dos clientes e a buscar a melhoria contínua da qualidade em uma organização.

O desempenho das organizações para Stan e Mărăscu (2012) depende de uma análise cuidadosa e sustentável dos processos, produtos e serviços no sentido de reduzir os custos de fabricação e oferecer qualidade. Ao utilizar técnicas, ferramentas, modelos ou programas de qualidade, a empresa pretende melhorar processos e então assegurar um padrão para seus produtos ou serviços. Portanto é necessário um sistema de qualidade para gerir todos os processos e efetivamente alcançar padrões de qualidade desejados (BAIRD; HU; REEVE, 2011).

Paladini (2008) diz que a concepção de qualidade se modificou ao longo do tempo acarretando mudanças relevantes em sua forma de gestão. Nesse processo, a qualidade deixa de ser vista como um problema a ser resolvido e passa a ser considerada oportunidade de vantagem competitiva frente à concorrência.

Uma vantagem competitiva surge quando uma empresa se antecipa às suas concorrentes, ou seja, as empresas conseguem ganhar vantagem competitiva temporária com a implementação de práticas da qualidade (SU et al., 2015). Para Pires (2012), a qualidade tem sempre várias dimensões e não se trata de um problema fabril/fornecimento de serviço, mas é cada vez mais um problema de fases anteriores começando desde logo pela identificação das necessidades do utilizador e na sua expressão em termos das funções que este deve desempenhar.

\subsection{Metodologia DMAIC}

Trata-se de um ciclo que pode ser utilizado de forma independente, mas sua aplicação é muito frequente em ferramentas de excelência operacional e em projetos Seis Sigma. Pode-se destacar que o ciclo DMAIC é uma extensão do ciclo PDCA (Plan-Planejar, Do-Fazer, Check-Checar, Act-Agir), que teve sua origem em 1950 no Japão, por meio do Dr. W. Edwards Deming e é utilizado para a melhoria contínua de produtos e processos (MONTGOMERY; WOODALL, 2008; SNEE, 2001; SOKOVIC et al., 2007).

Se a metodologia de melhoria for considerada como um processo, então a entrada para a este processo é o problema, a saída é a solução para o problema e o processo pode ser decomposto pelas cinco fases da metodologia (SHANKAR, 2009). Essa metodologia é utilizada para melhorar processos já existentes, 
além de eliminar defeitos, aumentar a satisfação dos clientes e, principalmente, aumentar a lucratividade das empresas (PRASHAR, 2014).

Segundo Escobar et al. (2012), a metodologia DMAIC representa um ciclo para desenvolver projetos de melhoria relacionados à qualidade, tanto em redução de defeitos, quanto em aumento de produtividade, ou redução de custos. As letras representam a sequência das etapas que devem ser desenvolvidas quando aplicada o método: Definir (Define), Medir (Measure), Analisar (Analyse), Melhorar (Improve) e Controlar (Contro). Esse modelo se refere a cinco etapas inter-relacionadas para garantir melhorias sistematicamente (JIRASUKPRASERT et al., 2014).

Dois pontos importantes sobre a metodologia também são destacados por Escobar (2012), que são: o alinhamento entre o projeto que vai ser iniciado e os indicadores-chave para o negócio da empresa, e o enfoque na mensuração das informações disponíveis. As etapas do ciclo DMAIC utilizam como suporte uma série de ferramentas e técnicas estatísticas que auxiliam no cumprimento dos objetivos específicos das etapas e, consequentemente, no objetivo geral do projeto.

\section{METODOLOGIA}

Para a coleta dos dados foram realizadas pesquisas de campo, onde foram feitas visitas in loco. Para aumentar a validade do constructo, esse estudo de caso utilizou várias fontes de evidências, como: documentos, registros em arquivo, entrevistas, observação direta e observação participante.

Neste estudo, foram utilizadas as ferramentas da qualidade e os procedimentos indicados pelo DMAIC. Isso permitiu acompanhar a produção e apontar as possíveis causas e efeitos dos desperdícios que afetam a qualidade do produto no processo. Para tal realização, o trabalho desdobrou-se em algumas fases (Figura 1), como demonstradas a seguir:

- Definição do problema: definiu-se o problema que foi trabalhado;

- Revisão bibliográfica: trazer conceitos fundamentais para a compreensão do desenvolvimento do projeto;

- Caracterização geral da indústria onde o trabalho foi elaborado;

- Definições do projeto: alinhamento com a estratégia da empresa, escopo, integrantes da equipe multidisciplinar, cronograma e metas;

- Estudo sobre o processo: estratificação das variáveis de interesse, investigação dos impactos e das causas dos problemas no processo;

- Priorização dos problemas encontrados, geração e seleção de soluções, e elaboração de planos de ação para eliminá-los ou minimizá-los. 
Figura 1 - Etapas da pesquisa

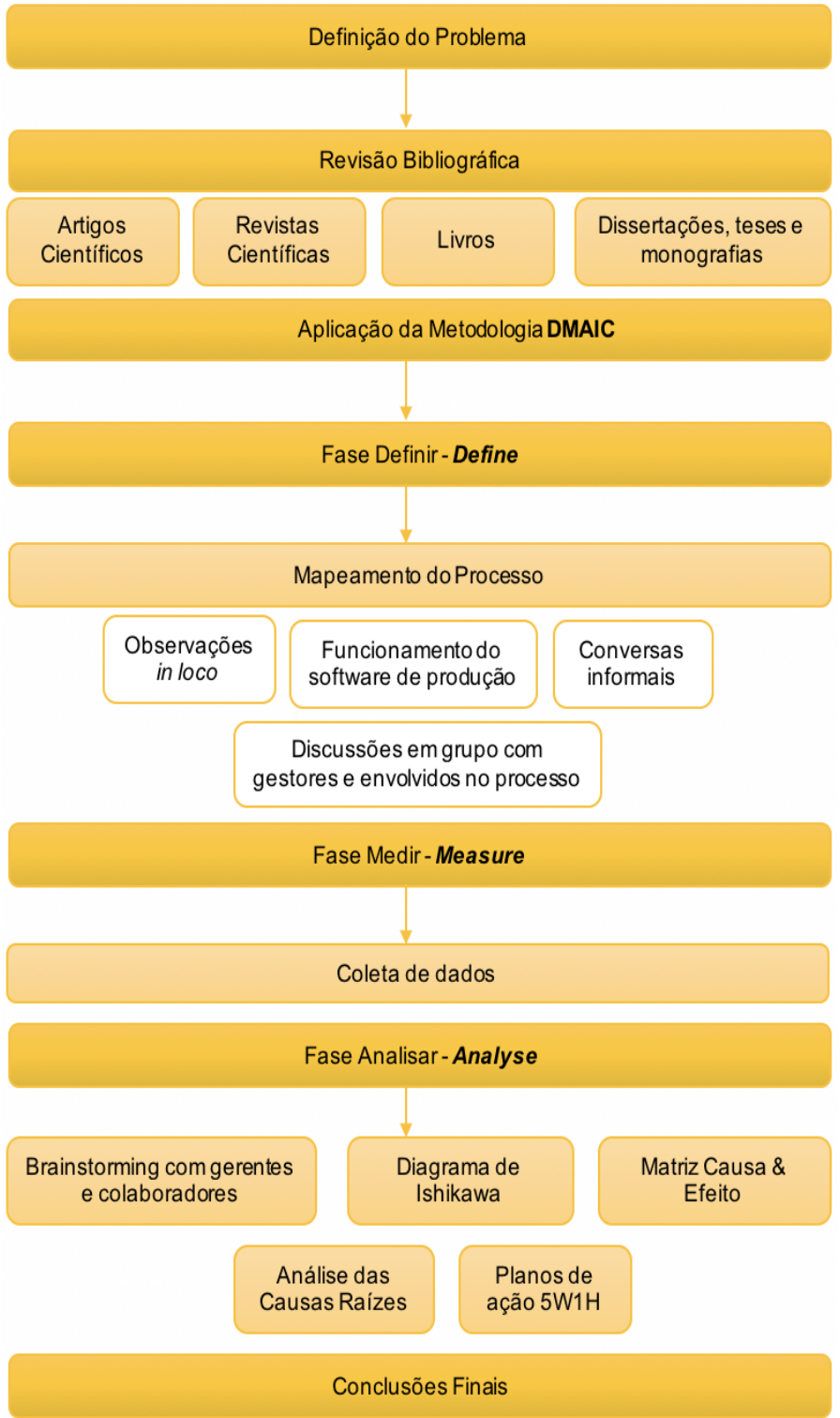

Fonte: Autoria própria (2021).

Como a aplicação da metodologia DMAIC é fator-chave para o desenvolvimento do trabalho, fez-se necessário detalhar suas etapas.

\subsection{Etapa Definir - DENIFE}

A etapa Definir iniciou-se com a delimitação do escopo do projeto, definição de metas, objetivos e processos chaves. Para facilitar o entendimento sobre processo em estudo foi construído o mapa do macroprocesso (SIPOC) do processo produtivo da empresa, o que facilitou a compreensão dos seus elementos chaves e fatores críticos de sucesso.

O SIPOC foi constituído por meio de informações sobre Fornecedores (Suppliers), Entradas (Inputs), Processo (Process), Saídas (Outputs) e Clientes (Customers), que foram coletadas através de observações in loco, de conversas informais com os envolvidos no processo e da investigação sobre o fluxo de informações no software de acompanhamento do processo de produção utilizado pela empresa. Reuniões com os gestores 
e responsáveis pelo setor em estudo, também são fontes de coleta de informações e serviram como base para o direcionamento do trabalho.

\subsection{Etapa Medir - MEASURE}

Estando com o escopo do projeto em mãos, suas metas e uma visão dos processos realizados dentro da indústria, iniciou-se a etapa Medir. Aqui, foram coletados os dados e tratados para serem transformados em informação. Foram identificadas também os KPIs (Key Performances Indicators) do trabalho.

Os dados amostrais foram coletados in loco, considerando os processos produtivos mais importantes para a quantificar os desperdícios. Os dados da produção e do gesso de limpeza (considerado rejeito) foram tratados com o auxílio do Microsoft Excel ${ }^{\oplus}$, posteriormente transformados em gráficos, para melhor análise. Os gráficos permitiram visualizar, de forma clara, o índice de desperdício baseado na produção.

\section{3;3 Etapa Analisar - ANALYSE}

Foram levantadas as causas, através de um brainstorming, para os desperdícios gerados na fábrica e aplicados os diagramas de Ishikawa. Ao final do preenchimento destes diagramas, as causas identificadas passaram por uma revisão técnica, um método de unificação de causas similares e descarte de causas incoerentes, resultando na seleção de causas prováveis. Esta revisão foi realizada pelos gerentes e responsáveis pelo setor de qualidade, para que então Matriz Causa e Efeito fosse aplicada.

O objetivo da aplicação desta técnica foi encontrar as causas potenciais dos desperdícios gerados nos processos, explanando em um ranking, as causas com maior impacto. Os gerentes e os colaboradores do chão de fábrica serviram como fontes de informações para composição dos Diagramas de Ishikawa, porém para elaboração da Matriz, apenas os gerentes e o diretor foram consultados, devido a maior complexidade da ferramenta.

Antes de finalizar o diagnóstico de causas potenciais, as causas em destaque no ranking foram analisadas quanto à natureza das raízes de suas causas, sendo assim distribuídas entre causas com raízes físicas, humanas e organizacionais. Por fim, foram construídos planos de ações - 5W1H (abreviatura que resume as perguntas a seguir: O quê? Quem? Onde? Quando? Por quê? Como?) com o objetivo de reduzir ou eliminar as causas fundamentais levantadas pela Matriz, adequando cada ação de melhoria ao nível organizacional cabível. Além disso, foram propostas melhorias complementares baseadas nas observações dos postos de trabalho, do layout da fábrica, do ambiente e da estrutura organizacional.

\section{RESULTADOS E DISCUSSÃO}

Nesta seção serão apresentadas os dados coletados e as respectivas informações extraídas a partir da metodologia aplicada.

\subsection{Aplicação do DMAIC}

A aplicação da metodologia DMAIC, foi desenvolvida baseada no referencial teórico efetuado no item 2, acompanhada de um período de observação de 4 dias e análise dos processos realizados dentro da empresa. O desenvolvimento desta metodologia restringiu-se apenas a aplicação das fases: Definir (Define), Medir (Measure), Analisar (Analyse). Ao finalizar tais etapas, foram elaborados alguns planos de ações com o objetivo de propor soluções para minimizar os problemas identificados, a fim de reduzir o número de desperdícios no processo. 


\section{- Etapa DEFINIR-DEFINE}

Nesta fase, definiu-se o problema chave, objetivos e metas, requisitos que compõe a carta do projeto. Para o desdobramento desta etapa, também se fez necessário determinar indicadores, limites deste projeto e a equipe de trabalho. Em seguida, elaborou-se o mapa do estado atual do processo (SIPOC), o que possibilitou identificar todas as etapas que o compõe, bem como a voz do cliente.

\section{- Carta do projeto}

O setor de produção foi selecionado como alvo deste trabalho devido aos depoimentos da alta direção, assim como da gerente de produção, que relataram o alto índice de desperdícios durante o processo produtivo do gesso gerando perdas consideráveis de tempo, matéria-prima e produto acabado.

Outro fator que levou a convergir para o problema chave definido, foi o levantamento de dados históricos da produção contendo a quantidade de big bags que foram coletados em um determinado período de produção, demonstrados com mais detalhes na fase seguinte (Medir). Deste modo, definiu-se como problema- chave a ser estudado, a solução dos problemas que geram desperdícios na linha de produção e elaborou-se a carta de projeto (Project Charter-Quadro 1).

Quadro 1 - Carta do Projeto

\begin{tabular}{|c|c|c|}
\hline \multicolumn{3}{|c|}{$\begin{array}{l}\text { Sumário Executivo } \\
\text { Contrato do Projeto }\end{array}$} \\
\hline \multicolumn{2}{|c|}{ Título: Solução de problemas que geram desperdício } & Líder: Ciro Fernandes \\
\hline Cliente: Diretor Geral & Área: Setor produtivo & Patrocinador: Diretor Geral \\
\hline \multicolumn{3}{|c|}{ Objetivo do projeto } \\
\hline \multicolumn{3}{|c|}{$\begin{array}{l}\text { Desenvolver a metodologia DMAIC dentro do setor produtivo da empresa, em busca da solução de problemas } \\
\text { que geram desperdícios. }\end{array}$} \\
\hline \multicolumn{3}{|c|}{ Histórico do problema } \\
\hline \multicolumn{3}{|c|}{$\begin{array}{l}\text { A partir do levantamento de dados históricos de desperdícios na produção, fornecido pela gerente de } \\
\text { produção, por diversos motivos a quantidade é alta, passando de } 100 \text { toneladas anuais. }\end{array}$} \\
\hline \multicolumn{2}{|l|}{ Definição da Meta } & KPIs do Projeto \\
\hline \multicolumn{2}{|c|}{$\begin{array}{l}\text { Reduzir em } 50 \% \text { a quantidade de gesso de limpeza comparando com o } \\
\text { primeiro semestre de } 2020 \text {. }\end{array}$} & $\begin{array}{l}\text { - Toneladas de gesso de } \\
\text { limpeza. }\end{array}$ \\
\hline \multicolumn{3}{|c|}{ Limites do Projeto (Inclui/Exclui) } \\
\hline $\begin{array}{l}\text { Inclui: Trabalhar com os } \\
\text { desperdícios a partir da etapa de } \\
\text { calcinação. }\end{array}$ & \multicolumn{2}{|c|}{$\begin{array}{l}\text { Exclui: Solucionar causas externas ao setor produtivo; Produção } \\
\text { terceirizada de gesso cola; rejeito de impurezas na etapa de britagem. }\end{array}$} \\
\hline \multicolumn{3}{|c|}{ Restrições do Projeto } \\
\hline \multicolumn{3}{|c|}{ Tempo para a realização do trabalho; Quantidade reduzida de visitas. } \\
\hline \multicolumn{3}{|c|}{ Requisitos do Cliente } \\
\hline \multicolumn{3}{|c|}{ Reduzir o número de desperdícios no processo produtivo, que é contabilizado como gesso de limpeza. } \\
\hline \multicolumn{3}{|c|}{ Contribuições para o negócio } \\
\hline
\end{tabular}

Fonte: Autoria própria (2021)

Para compreender melhor o problema, buscou-se investigar através dos relatórios e dados fornecidos pela gerente de produção, o histórico de desperdícios, para então iniciar as tomadas de decisões. Já que o 
desperdício na etapa de britagem não é misturado aos provenientes dos outros processos, pois é considerado como impróprio por conter muitas impurezas provenientes das minas (vestígios de explosivos, areia etc.), foi decidido não o considerar. Para análise, resolveu-se estudar os desperdícios a partir da etapa de calcinação.

Através dos dados fornecidos pela empresa, foram contabilizados 109,5 t de gesso de limpeza (gesso proveniente da limpeza da fábrica) durante o período de um ano. A meta foi estabelecida com base neste número e a partir da demanda do Diretor, visando reduzir no mínimo $50 \%$ do valor atual e buscando ultrapassar este percentual. Para a meta determinada estima-se que este número caia para aproximadamente 54 toneladas por ano.

\subsection{Equipe de trabalho}

O próximo passo foi a definição da equipe de trabalho (Quadro 3), que também compõe a carta do projeto. Aqui, estabeleceu-se os funcionários que colaboraram para o desenvolvimento do projeto, assim como para coleta de informações e composição das ferramentas aplicadas. A equipe contou com 11 colaboradores: o diretor geral da empresa, a gerente de produção que está no chão de fábrica diariamente acompanhando a produção, o mecânico que realiza manutenções, 02 calcinadores, 02 balanceiros, 03 da equipe de gestão e um estudante de Engenharia de Produção, responsável por liderar o projeto.

\subsection{Mapeamento do processo}

Obteve-se uma visualização mais clara do processo produtivo do gesso através do seu mapa SIPOC (Figura 2), que destaca cada passo desenvolvido pelas partes atuantes. É importante relembrar que existem 3 equipes de 3 colaboradores na fábrica, operando cada uma em um turno (total de 03). 0 desenvolvimento das atividades relativas a este setor é definido pela gerente de produção e direcionadas a cada equipe e seus colaboradores. Por exemplo, a etapa de britagem tem um britador responsável por operar a britadeira. Já na calcinação, o calcinador envia os comandos através do sistema de acionamento de motores automáticos no computador e abastece o forno com lenha. Este sistema utilizado permite o acionamento de motores e o desligamento deles, além de informar o tempo de processamento de cada forno.

Figura 2 - Processo de produção de gesso

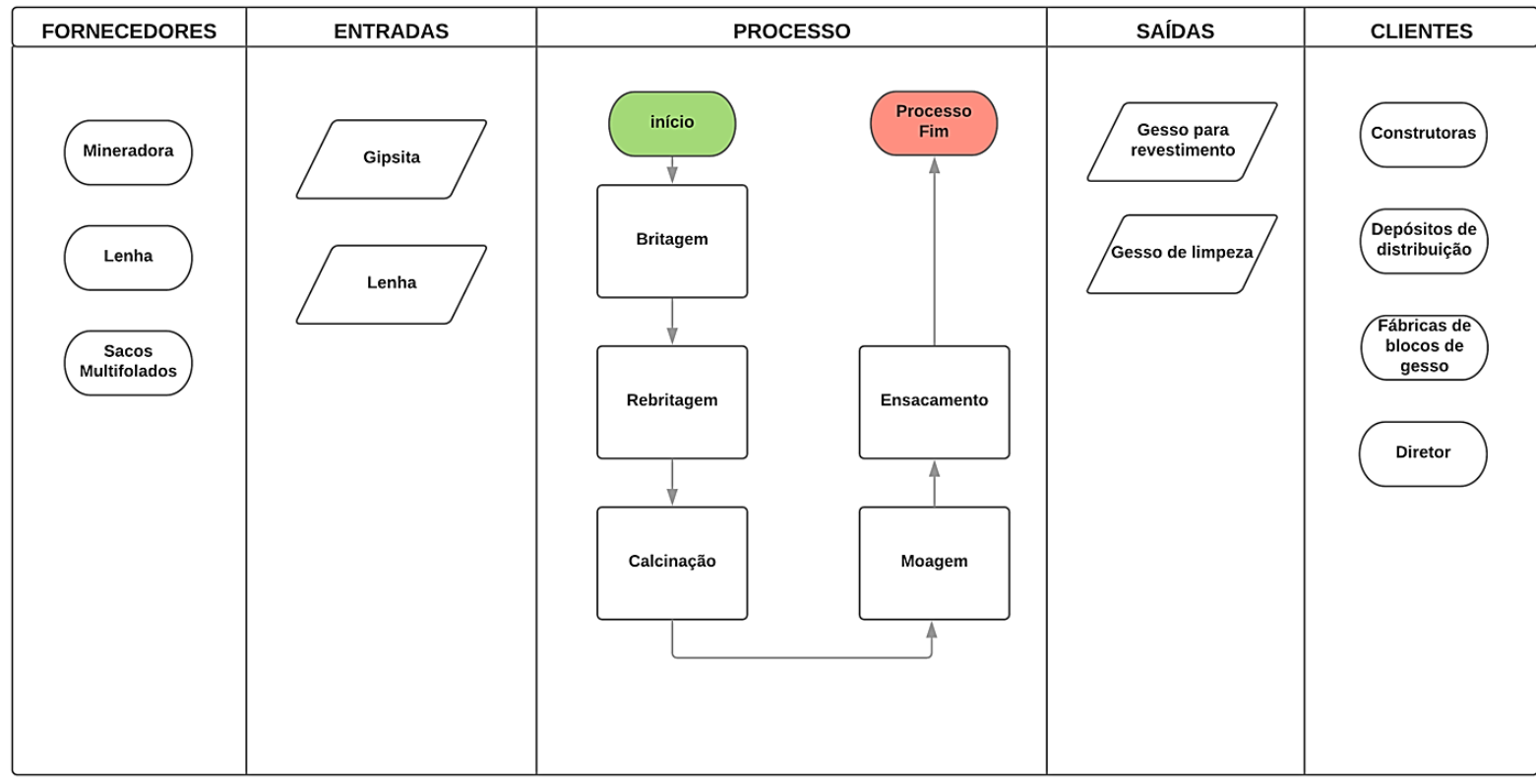

Fonte: Autoria própria (2021) 
Na produção de gesso, pode-se considerar a etapa de calcinação como a principal, já que é nela que se obtém o produto. Considerando isso, o processo inicia-se com etapas que preparam a matéria prima para a calcinação, visando facilitar e acelerar esse processo. Dessa forma, tudo começa com a britagem em um britador de mandíbula. Processo em que o minério gipsita, obtida nas reservas próximas à fábrica, com tamanhos que variam de 50 a $400 \mathrm{~mm}$ são fragmentados a aproximadamente 30 a $50 \mathrm{~mm}$. Logo em seguida, esses blocos são direcionados através de uma esteira para o rebritador, diminuindo a granulometria da pedra para tamanhos que variam de 0 a $5 \mathrm{~mm}$. Esses processos visam aumentar a área de contato com o calor, facilitando a retirada das moléculas de água no momento da calcinação.

Após a rebritagem, inicia-se a calcinação com a utilização de fornos à lenha classificados como "barriga d'água". A lenha é depositada na fornalha no início e durante a calcinação para que alcance a temperatura de obtenção do gesso, cerca de 175 graus centígrados. Essa etapa consiste na remoção da água de cristalização através da desidratação térmica do mineral para que este se torne um produto útil para a construção civil. O fim do processo se dá pelo acompanhamento da temperatura do forno, disponível na sala técnica. Quando atingida, o calcinador finaliza a batelada dando o comando de parada no computador e despeja o gesso na masseira.

O gesso obtido após a calcinação do minério é normalmente moído em moinho de martelos para moagem fina e obtenção da granulometria final especificada pela ABNT 13207 (ASSOCIAÇÃO BRASILEIRA DE NORMAS TÉCNICAS, 1994). Esse processo é contínuo e não tem um operador. O ensacamento é o último processo. O gesso moído é encaminhado para um silo de armazenamento, o qual possui em sua extremidade uma máquina ensacadeira. O Gesso é embalado em sacos multifoliados de papel, contendo $40 \mathrm{~kg}$. Logo em seguida são pesados e encaminhados para a expedição ou para a fabricação de placas e blocos.

\subsection{Etapa Medir - Measure}

A etapa Medir iniciou-se com o levantamento de dados históricos da quantidade de gesso de limpeza coletado mensalmente no setor produtivo. A partir dos dados coletados, é possível notar que para o mês de janeiro de 202 , foram produzidas 2153,67 toneladas de gesso de revestimento. No mesmo mês foram geradas 20,56 toneladas de gesso de limpeza que representam cerca de $0,95 \%$ da produção. Nos meses de fevereiro e março esses percentuais foram de, respectivamente, $0,80 \%$ e 0,64\%. Apesar do comparativo demonstrar alta produção e aparentemente uma baixa representatividade do gesso de limpeza comparada com a produção, esses números quando expostos em valores monetários podem chamar mais atenção.

Foram contabilizadas um total de 5796,29 toneladas de gesso de revestimento e 47,06 toneladas de gesso de limpeza durante o período de três meses (jan/fev/mar 2021). É importante ressaltar que esse quantitativo não inclui o rejeito proveniente da etapa de britagem, pois não é misturado ao gesso de limpeza já que ainda não foi calcinado e não é considerado gesso. Portanto, esse trabalho teve como foco os desperdícios da etapa de calcinação, moagem, ensacamento e armazenagem que são consideradas as que mais geram desperdício.

Fazendo uma análise básica com os preços de venda dos produtos na empresa, pode-se afirmar que atualmente o saco de gesso com $40 \mathrm{~kg}$ é vendido à $R \$ 9,46$ ( $R \$ 236,50$ a tonelada), enquanto a tonelada do gesso de limpeza é vendida por $\mathrm{R} \$ 60,00$. A diferença no preço de venda da tonelada é alta e chega a $394,17 \%$, ou seja, o gesso de revestimento é vendido à quase 4 vezes o preço do gesso de limpeza. No tocante ao faturamento da empresa, foi registrado um total de $\mathrm{R} \$ 1.373 .646,19$ considerando gesso de limpeza e de revestimento.

Considerando a demanda do diretor da empresa, na carta do projeto, solicitando a redução de $50 \%$ dos desperdícios, pode-se estimar para esse período de 3 meses o faturamento considerando essa redução (Tabela 1). O gesso de limpeza que hipoteticamente teria sua representatividade reduzida em $50 \%$, ou seja, cairia para 23,53 toneladas enquanto a outra metade seria convertida automaticamente em gesso de revestimento. 
Tabela 1 - Faturamento trimestral

\begin{tabular}{ccccccc}
\hline & $\begin{array}{c}\text { Nova produção } \\
\text { no trimestre (t) }\end{array}$ & $\begin{array}{c}\text { Novo faturamento no } \\
\text { trimestre }\end{array}$ & Aumento / Redução \\
\hline $\begin{array}{c}\text { Gesso de } \\
\text { revestimento }\end{array}$ & 5819,82 & $\mathrm{R} \$$ & $1.376 .387,43$ & $\mathrm{R} \$$ & $+5.564,84$ \\
$\begin{array}{c}\text { Gesso de limpeza } \\
\text { Total }\end{array}$ & 23,53 & $\mathrm{R} \$$ & $1.411,80$ & $\mathrm{R} \$$ & $-1.411,80$ \\
& 5843,35 & $\mathrm{R} \$$ & $1.377 .799,23$ & $\mathrm{R} \$$ & $+4.153,04$ \\
\hline
\end{tabular}

Fonte: Dados da pesquisa (2021)

Dessa forma, se das 47,06 toneladas de rejeito, 23,53 (50\%) fossem vendidas como gesso de revestimento por $\mathrm{R} \$ 236,50$ a tonelada, elas trariam um aumento de pelo menos $R \$ 5564,85$ no faturamento de gesso de revestimento para a indústria no período de 3 meses. Essas mesmas 23,53 toneladas vendidas no preço atual de gesso de limpeza retornam somente $\mathrm{R} \$ 1411,80$, ou seja, evitar os desperdícios durante o processo produtivo pode trazer ganhos financeiros consideráveis para a empresa.

\subsection{Etapa Analisar}

Foram consideradas as etapas de produção da fase anterior, para análise de suas causas. Estas, foram feitas a partir da aplicação de diagramas de Ishikawa para cada processo (reservados apenas para consulta da empresa). Em seguida, realizou-se um tratamento nas informações obtidas pelo diagrama. A partir deste tratamento, pôde-se elaborar a matriz causa-efeito, para relacionar cada defeito a cada problema específico e quantificar seus respectivos impactos. Finalizada a composição e preenchimento da matriz, obteve-se uma escala demonstrando as causas que possuíam um maior número de correlações com outros processos e geradoras de maiores impactos. Por meio desses resultados, destacou-se as causas-alvos que seriam priorizadas na elaboração de planos de ações de melhoria.

Os diagramas de Ishikawa aplicados foram direcionados para cada um dos 4 processos destacados na etapa anterior: calcinação/masseira, moinho, ensacamento e armazenagem. Na Tabela 2, encontra-se cada processo e seu respectivo número de possíveis causas encontradas na elaboração dos diagramas de Ishikawa.

Tabela 2 - Causas versus processos

\begin{tabular}{cc}
\hline Processos & Número de causas \\
\hline Calcinação/masseira & 8 \\
Moinho & 7 \\
Ensacamento & 6 \\
Armazenagem & 8 \\
Total & 29 \\
\hline
\end{tabular}

Fonte: Dados da pesquisa (2021)

Foram encontradas 29 possíveis causas, porém antes de seguir para a composição da matriz causaefeito, estas foram tratadas através de análises de validação com a gerente de produção e o diretor da empresa, na tentativa de uniformizar as causas similares e desconsiderar causas incoerentes. Após o tratamento todas 
as causas foram mantidas para construção das Matrizes Causa e Efeito (disponível para consulta apenas à empresa).

Os processos estudados foram posicionados no eixo horizontal da tabela, e as causas no eixo vertical, para que então fosse possível avaliar o impacto de cada causa nos respectivos defeitos. Dentre elas, existem causas específicas de determinados processos, assim como causas que são aplicáveis a maioria dos processos.

Na matriz causa e efeito, as avaliações de relação das causas com cada defeito foram realizadas apenas pela gerente de produção, que ao fim do seu preenchimento e soma, resultou em um ranking das causas que exercem maior impacto nos defeitos levantados. Estas causas foram avaliadas não apenas pelo caráter técnico dos eventos, mas também com base na realidade observada dentro da empresa, e do seu quadro de funcionários. A Tabela 3 apresenta as causas com maiores índices de gravidade. Esses índices foram obtidos a partir da correlação entre as causas e os desperdícios gerados em cada etapa do processo produtivo.

Tabela 3 - Ranking de causas identificadas

\begin{tabular}{clcc}
\hline Posição & \multicolumn{1}{c}{ Causa } & Pontuação & \\
\hline $\mathbf{1}^{\mathbf{0}}$ & Operário descompromissado & 14 & $\mathrm{O}$ \\
$\mathbf{2}^{\mathbf{0}}$ & Operário desqualificado & 12 & $\mathrm{O}$ \\
$\mathbf{3}^{\circ}$ & Falta de padronização da quantidade de massa & 11 & $\mathrm{O}$ \\
$\mathbf{4}^{\circ}$ & Sacos com defeito, velhos ou furados & 10 & $\mathrm{~F}$ \\
$\mathbf{5}^{\circ}$ & Acesso difícil & 9 & $\mathrm{O}$ \\
$\mathbf{6}^{\circ}$ & Temperaturas elevadas & 6 & $\mathrm{~F}$ \\
$\mathbf{7 0}^{\mathbf{O}}$ & Peças desgastadas & 6 & $\mathrm{~F}$ \\
O-Organizacionais & H-Humanas & F- Físicas & \\
\hline
\end{tabular}

Fonte: Dados da pesquisa (2021)

Após a obtenção do ranking das causas com maiores índices, onde estes poderiam variar em uma escala de 0 a 14, foram destacadas sete causas raízes. Optou-se por priorizar e propor ações de melhoria para apenas sete das causas, devido à complexidade e importância de resolução destas. Constatou-se que dentre as sete citadas anteriormente existem três naturezas de origem distintas atuantes, dividindo-as em: raízes físicas, humanas e organizacionais. Para então, por fim, elaborar os Planos de Ações de Melhorias como sugestões para redução do impacto gerado por estas causas.

\subsection{Plano de ação}

Foram propostas ações para minimizar a ocorrência de desperdícios com sacos velhos, rasgados ou furados com a sugestão da elaboração de uma Folha de Verificação do estado dos sacos no momento da saída e do retorno à fábrica para que se tenha controle sobre o estado dos big bags (embalagem para transportar materiais de natureza sólida ou pastosa) e garantir que os que retornam ainda podem ser utilizados. Também foi proposto adicionar identificação com data de compra aos sacos para que se tenha noção do ciclo de vida útil deles. E por fim, a proposta da armazenagem em local apropriado para garantir que não aconteçam acidentes e para que a vida útil do produto seja bem aproveitada.

O Plano de Ação (Quadro 2) propõe ainda ações para minimizar a ocorrência de desperdícios com peças desgastadas, ou seja, ações corretivas que visam fazer trocas periódicas das peças e componentes das máquinas usadas no chão de fábrica. Foi proposto manutenção preventiva periódica para manter as máquinas e peças em bom funcionamento e a criação de uma planilha com planejamento de manutenção, auxiliando o direcionamento das manutenções a serem realizadas. 
Tem-se ações para minimizar a ocorrência de temperaturas elevadas sugerindo a instalação de exaustores no teto da fábrica visando melhorar a temperatura dentro da fábrica e tornar o trabalho mais agradável para os trabalhadores. Além disso sugere-se também organizar uma escala de horários de trabalho objetivando evitar que os colaboradores acessem os locais considerados muito quentes, evitando acidentes e para que as configurações nas máquinas e equipamentos sejam feitas periodicamente em segurança.

Deve-se salientar que o presente estudo pôs em destaque quatro causas com raízes organizacionais, nas quais existe a possibilidade de serem indiretamente responsáveis pelas causas anteriores, as classificadas como físicas. São as seguintes causas: operário descompromissado, operário desqualificado, falta de padronização da quantidade de massa, acesso difícil.

Alguns aspectos observados na empresa são a falta de envolvimento de alguns funcionários, defasagem na comunicação, tarefa tida como indesejada pelo colaborador (manuseio de materiais pesados, trabalhar em ambientes quentes), não observância de procedimentos, falta de capacitação, utilização ferramental incorreta ou desgastada, prioridades incorretas, falta de acesso a informação. 
Quadro 2 - Plano de Ação

\begin{tabular}{|c|c|c|c|c|c|}
\hline O quê? & Por quê? & Quando? & Onde & Como & Quem \\
\hline $\begin{array}{c}\text { Elaborar uma Folha de } \\
\text { Verificação do estado dos sacos } \\
\text { no momento da saída e do } \\
\text { retorno à fábrica }\end{array}$ & $\begin{array}{l}\text { Para ter controle sobre o estado dos big } \\
\text { bagse garantir que os que retornam } \\
\text { ainda podem ser utilizados. }\end{array}$ & $\begin{array}{l}\text { Em até duas } \\
\text { semanas. }\end{array}$ & $\begin{array}{l}\text { No setor de } \\
\text { compras. }\end{array}$ & $\begin{array}{l}\text { Utilizando Excel } \AA \\
\text { Quais os principais dados que } \\
\text { compõem essa FV? }\end{array}$ & $\begin{array}{l}\text { Responsável pelo } \\
\text { setor de compras. }\end{array}$ \\
\hline $\begin{array}{l}\text { Adicionar identificação com data } \\
\text { de compra aos sacos. }\end{array}$ & $\begin{array}{l}\text { Para que se tenha noção ciclo de vida } \\
\text { útil dos sacos. }\end{array}$ & $\begin{array}{l}\text { Sempre que } \\
\text { houver sacos } \\
\text { novos ou sem } \\
\text { identificação. }\end{array}$ & $\begin{array}{l}\text { No setor de } \\
\text { distribuição. }\end{array}$ & Com um pincel de escrita permanente. & $\begin{array}{l}\text { Carregadores ou } \\
\text { responsável pelo } \\
\text { despacho e estoque. }\end{array}$ \\
\hline $\begin{array}{l}\text { Armazenar as embalagens em } \\
\text { local apropriado. }\end{array}$ & $\begin{array}{l}\text { Para garantir que não aconteçam } \\
\text { acidentes e para garantir uma vida útil } \\
\text { maior. }\end{array}$ & $\begin{array}{l}\text { Sempre que } \\
\text { forem recebidas. }\end{array}$ & $\begin{array}{l}\text { Setor de } \\
\text { distribuição }\end{array}$ & $\begin{array}{l}\text { Definindo espaços apropriados e } \\
\text { demarcando com fitas. Prateleiras } \\
\text { também podem ser instaladas. }\end{array}$ & $\begin{array}{l}\text { Responsáveis pelo } \\
\text { setor de } \\
\text { distribuição. } \\
\end{array}$ \\
\hline $\begin{array}{l}\text { Manutenção preventiva } \\
\text { periódica. }\end{array}$ & $\begin{array}{l}\text { Para manter as máquinas e peças em } \\
\text { bom funcionamento. }\end{array}$ & Mensalmente. & Setor produtivo. & $\begin{array}{c}\text { Fazendo inspeções, manutenções e } \\
\text { trocas em peças e máquinas que } \\
\text { necessitem. }\end{array}$ & Mecânico. \\
\hline $\begin{array}{l}\text { Criar planilha com planejamento } \\
\text { de manutenção. }\end{array}$ & $\begin{array}{l}\text { Auxiliar o direcionamento das } \\
\text { manutenções a serem realizadas. }\end{array}$ & Em um mês. & $\begin{array}{l}\text { Setor produtivo e } \\
\text { de manutenções. }\end{array}$ & $\begin{array}{c}\text { Utilizando o Excel } \\
\text { Quais são as principais atividades que } \\
\text { devem ter nesta planilha? }\end{array}$ & $\begin{array}{l}\text { Gerente de } \\
\text { Produção. }\end{array}$ \\
\hline Instalação de exaustores no teto. & $\begin{array}{l}\text { Para melhorar a temperatura dentro da } \\
\text { fábrica e tornar o trabalho mais } \\
\text { agradável para os trabalhadores. }\end{array}$ & $\begin{array}{l}\text { Em até um } \\
\text { semestre. }\end{array}$ & Setor produtivo. & $\begin{array}{l}\text { Contratando uma empresa que venda } \\
\text { e instale exaustores. }\end{array}$ & Diretor. \\
\hline $\begin{array}{l}\text { Organizar horário de trabalho } \\
\text { para locais muito quentes. }\end{array}$ & $\begin{array}{c}\text { Evitar que haja acidentes e para que } \\
\text { sejam feitas as configurações } \\
\text { necessárias. }\end{array}$ & $\begin{array}{l}\text { Em até duas } \\
\text { semanas. }\end{array}$ & $\begin{array}{l}\text { Setor produtivo e } \\
\text { de manutenções. }\end{array}$ & $\begin{array}{l}\text { Utilizando o Excel como ferramenta } \\
\text { organizando os melhores horários para } \\
\text { se trabalhar em locais quentes. }\end{array}$ & $\begin{array}{l}\text { Gerente de } \\
\text { Produção. }\end{array}$ \\
\hline Realizar reuniões. & $\begin{array}{l}\text { Para unir a equipe e traçar diretrizes de } \\
\text { curto prazo. }\end{array}$ & Mensalmente. & $\begin{array}{l}\text { Laboratório ou } \\
\text { Setor produtivo. }\end{array}$ & $\begin{array}{l}\text { Convidando as equipes de trabalho } \\
\text { para orientar sobre o planejamento da } \\
\text { produção. }\end{array}$ & $\begin{array}{l}\text { Gerente de } \\
\text { produção. }\end{array}$ \\
\hline $\begin{array}{l}\text { Realizar treinamentos e/ou } \\
\text { palestras. }\end{array}$ & $\begin{array}{l}\text { Para tornar o operário conhecedor do } \\
\text { que ele faz. }\end{array}$ & $\begin{array}{l}\text { Mensalmente e } \\
\text { quando entrar } \\
\text { um novo } \\
\text { funcionário. }\end{array}$ & Setor produtivo. & $\begin{array}{l}\text { Convidando instituições de ensino e de } \\
\text { consultorias. }\end{array}$ & $\begin{array}{l}\text { Gerente de } \\
\text { Produção. }\end{array}$ \\
\hline $\begin{array}{l}\text { Melhorar o contato entre } \\
\text { funcionários da empresa. }\end{array}$ & $\begin{array}{l}\text { Para tornar o ambiente de trabalho mais } \\
\text { harmônico. }\end{array}$ & Semanalmente. & Na empresa. & $\begin{array}{c}\text { Criando um espaço de convivência e } \\
\text { tornando os setores abertos uns aos } \\
\text { outros. }\end{array}$ & Diretor. \\
\hline $\begin{array}{l}\text { Promover atividades de lazer } \\
\text { entre funcionários. }\end{array}$ & $\begin{array}{l}\text { Para torná-los mais próximos e mais } \\
\text { comunicativos. }\end{array}$ & $\begin{array}{c}\text { A cada } 2 \text { ou } 3 \\
\text { meses. }\end{array}$ & $\begin{array}{l}\text { Chácaras, } \\
\text { restaurantes, } \\
\text { pizzarias etc. }\end{array}$ & $\begin{array}{c}\text { Criando um calendário de atividades } \\
\text { de lazer de acordo com os recursos } \\
\text { disponíveis. }\end{array}$ & Setor financeiro. \\
\hline $\begin{array}{l}\text { Reconhecer o trabalho dos } \\
\text { funcionários. }\end{array}$ & $\begin{array}{c}\text { Para que eles se sintam reconhecidos e } \\
\text { motivados. }\end{array}$ & Sempre. & $\begin{array}{l}\text { Em conversas } \\
\text { informais, formais e }\end{array}$ & $\begin{array}{l}\text { Bonificando no salário ou } \\
\text { reconhecendo verbalmente. }\end{array}$ & $\begin{array}{l}\text { Gerente de } \\
\text { produção. }\end{array}$ \\
\hline
\end{tabular}

ISSN 2237-4558 • Navus • Florianópolis • SC • v. 11 • p. 01-19 • jan./dez. 2021 


\begin{tabular}{|c|c|c|c|c|c|}
\hline & & & $\begin{array}{l}\text { sempre que for } \\
\text { merecido. }\end{array}$ & & \\
\hline $\begin{array}{l}\text { Programa motivacional e de } \\
\text { valorização dos funcionários. }\end{array}$ & $\begin{array}{l}\text { Aumentar a satisfação de fazer parte da } \\
\text { empresa, bem como o } \\
\text { comprometimento, empenho e } \\
\text { dedicação ao seu trabalho. }\end{array}$ & Mensalmente. & Toda empresa. & $\begin{array}{l}\text { Colocando em prática algumas ações } \\
\text { como a escolha do funcionário do mês, } \\
\text { palestras e programas de cuidados } \\
\text { com a saúde do trabalhador, } \\
\text { homenagens a funcionários que } \\
\text { possuem mais tempo na empresa, } \\
\text { eventos comemorativos etc. }\end{array}$ & $\begin{array}{l}\text { Gerente de } \\
\text { Produção e o } \\
\text { Diretor. }\end{array}$ \\
\hline Plano de Carreira. & $\begin{array}{l}\text { Estimular a produtividade e o } \\
\text { crescimento profissional dos } \\
\text { funcionários, em busca de melhores } \\
\text { resultados para ambos } \\
\text { (empresa/funcionário). }\end{array}$ & $\begin{array}{l}\text { Apresentá-lo no } \\
\text { momento da } \\
\text { contratação. }\end{array}$ & Setor Financeiro. & $\begin{array}{l}\text { Redefinir organograma, delimitando as } \\
\text { responsabilidades e lideranças por } \\
\text { níveis de atuação, de modo a } \\
\text { descentralizar da gerente de produção } \\
\text { toda a responsabilidade. Estabelecer } \\
\text { competências e projetos que devem } \\
\text { ser desenvolvidos pelos funcionários } \\
\text { para seu crescimento. }\end{array}$ & $\begin{array}{l}\text { Setor de RH (quando } \\
\text { houver). }\end{array}$ \\
\hline $\begin{array}{l}\text { Programa de Qualificação } \\
\text { interna. }\end{array}$ & $\begin{array}{l}\text { Aumentar o nível de qualificação dos } \\
\text { funcionários. }\end{array}$ & $\begin{array}{l}\text { Um final de } \\
\text { semana por mês. } \\
\text { Obs.: Também } \\
\text { deve ser } \\
\text { realizado com a } \\
\text { admissão de um } \\
\text { novo funcionário }\end{array}$ & $\begin{array}{l}\text { Na sede da } \\
\text { empresa / } \\
\text { laboratório. }\end{array}$ & $\begin{array}{c}\text { Exposição de conteúdos em slidese } \\
\text { materiais impressos. Aula explicativa e } \\
\text { prática. }\end{array}$ & $\begin{array}{l}\text { Instrutor externo, } \\
\text { com o suporte da } \\
\text { gerente de } \\
\text { produção. }\end{array}$ \\
\hline $\begin{array}{l}\text { Bonificação de funcionários por } \\
\text { cursos finalizados. }\end{array}$ & $\begin{array}{l}\text { Estimular os funcionários a participarem } \\
\text { do Programa de Qualificação e obter } \\
\text { bons resultados. }\end{array}$ & $\begin{array}{l}\text { Ao fim de cada } \\
01,02,03 \\
\text { módulos, ou } \\
\text { mais. Variando de } \\
\text { acordo com a } \\
\text { bonificação. }\end{array}$ & $\begin{array}{l}\text { Em todos os } \\
\text { setores. }\end{array}$ & $\begin{array}{l}\text { Premiando-os com: passeios, jantares, } \\
\text { churrascos, equipamentos eletrônicos, } \\
\text { dias adicionais às férias, } 144^{\circ} \text { salário, } \\
\text { entre outros. Definido de acordo com } \\
\text { os recursos disponíveis. }\end{array}$ & Setor RH. \\
\hline $\begin{array}{l}\text { Estabelecer uma abertura de } \\
\text { gaveta-padrão } \\
\text { ou automatizá-la. }\end{array}$ & $\begin{array}{c}\text { Para que as roscas de transporte não } \\
\text { entupam com a alta quantidade de } \\
\text { massa. }\end{array}$ & Imediatamente. & Na masseira. & $\begin{array}{l}\text { Tornando a gaveta fixa através de solda } \\
\text { ou com sua adaptação automática ao } \\
\text { fluxo produtivo. }\end{array}$ & Mecânico. \\
\hline $\begin{array}{c}\text { Criar alternância entre os fornos } \\
\text { para que deformem em tempos } \\
\text { diferentes. }\end{array}$ & $\begin{array}{l}\text { Evitar que as roscas entupam com o alto } \\
\text { fluxo de massa. }\end{array}$ & Imediatamente. & Na calcinação. & $\begin{array}{l}\text { Como o tempo de calcinação é de } \\
\text { cerca de } 1 \text { h10, criar um padrão de } \\
\text { produção para deformar a cada } 40 \text { min. }\end{array}$ & $\begin{array}{l}\text { Calcinador / Gerente } \\
\text { de produção. }\end{array}$ \\
\hline $\begin{array}{l}\text { Utilizar acessórios que facilitem } \\
\text { o acesso a determinados locais. }\end{array}$ & $\begin{array}{l}\text { Para que os colaboradores trabalhem } \\
\text { com segurança e para que se possa } \\
\text { realizar o trabalho da melhor forma } \\
\text { possível. }\end{array}$ & $\begin{array}{l}\text { Sempre que } \\
\text { necessário. }\end{array}$ & Masseira e moinho. & $\begin{array}{l}\text { Solicitando a instalação de uma escada } \\
\text { pequena para o moinho e um acesso } \\
\text { para a masseira. }\end{array}$ & $\begin{array}{l}\text { Mecânico e setor } \\
\text { financeiro. }\end{array}$ \\
\hline
\end{tabular}

Fonte: Dados da pesquisa (2021) 
É importante sugerir ações além das pontuadas nos itens anteriores para que sirvam de complemento e para que a abrangência das ações tomem proporções maiores e mais eficazes. Diversos problemas foram percebidos durante as observações in loco e muitas melhorias podem ser feitas no setor produtivo, no setor de manutenções e no setor administrativo.

Com relação ao setor produtivo, algumas ações poderiam ser feitas, como por exemplo: as marcações de layout com fitas coloridas para delimitar as áreas de segurança, de passeio, de acesso restrito etc.; a implantação da estratégia FIFO (primeiro lote/produto que entra é o primeiro que sai) para que se tenha um giro correto e organizado do estoque; aproximar o laboratório de qualidade do setor de produção para que os estudos de qualidade (tempo de pega) sejam executados mais rapidamente e para que a tomada de decisão de um lote fora de controle também seja mais rápida; estratificar os desperdícios por processo para que se tenha um controle maior para a tomada de decisão sobre os desperdícios.

Implantar ensacadeiras modernas para acabar com os desperdícios na etapa de ensacamento; padronizar a quantidade de lenha necessária para uma fornada de calcinação, construindo prateleiras com espaços para lenha necessária para uma calcinação. Essa última ação reduziria os desperdícios com a utilização de energia desnecessária.

É importante citar que foi observado que os fornos de calcinação possuíam diferenças no tempo de calcinação e no consumo de lenha para produzir a mesma quantidade de sacos de gesso. Enquanto o forno 1 consumia mais lenha, o forno 2 consumia uma quantidade menor e tinha um tempo de calcinação de 10 a 15 minutos a menos que o forno 1.

Diante dessa problemática, foram analisadas as possíveis causas do problema e foi descoberto que essa diferença é ocasionada porque o nível de matéria-prima dos silos de enchimento dos fornos estão iguais, ou seja, o forno 1, que tem uma capacidade maior e pode calcinar mais gipsita, está sendo cheio com a mesma capacidade do forno 2 que tem capacidade menor. Para corrigir esse problema, uma proposta, levantada em uma das reuniões com a equipe de trabalho é que seja nivelada a boia do silo do forno 1 de acordo com sua verdadeira capacidade para que se economize lenha e para ter ganho na produtividade. Para uma análise mais aprofundada desse caso, seriam necessários estudos mecânicos e químicos mais aprofundados, no sentido de melhorar a eficiência e a produtividade deste processo de calcinação.

\section{CONCLUSÃO}

A metodologia DMAIC permitiu levantar os elementos necessários para o desenvolvimento do trabalho, sem que houvesse distanciamento do problema central. Na etapa Definir foi possível encontrar tais respostas, as quais nortearam os próximos passos do trabalho. O mapeamento do processo, elaborado por meio do mapa SIPOC (técnica que associa as iniciais, em inglês, de cada aspecto analisado pela ferramenta: Supplier, Input, Process, Outputs e Customer), foi uma ferramenta que, ao aplicá-la pôde-se identificar com clareza os reais clientes do processo, suas exigências, como todo o processo é desenvolvido e os responsáveis por cada etapa.

Neste trabalho fatores como: baixo preço de compra, tempo de pega longo, granulometria, massa do saco e o armazenamento de acordo com as especificações técnicas da ABNT 13207 foram compreendidos como requisitos dos clientes.

A clareza sobre tais requisitos viabilizou o andamento do trabalho, partindo para um processo de coleta de dados, para melhor esclarecimento da representatividade dos desperdícios perante a produção, explorados na etapa Medir. Esta etapa foi iniciada com a análise do número de desperdícios e de um estudo básico financeiro considerando os preços de venda de cada tipo de gesso em um período de três meses. Com isso, observou-se que se as 47,06 t de rejeito (gesso de limpeza), 23,53 (50\%) fossem vendidas como gesso de revestimento por $\mathrm{R} \$ 236,50$ a tonelada, elas trariam um aumento de pelo menos $R \$ 5.564,85$ no faturamento de gesso de revestimento para a indústria no período de 3 meses.

$\mathrm{Na}$ etapa Analisar, os resultados do diagrama de Ishikawa e da matriz Causa e Efeito, destacaram-se sete causas com maiores índices na avaliação. Em seguida, com a categorização das raízes das sete causas explanadas no ranking. Como foi percebido através dos resultados encontrados, onde as causas físicas - sacos 
com defeito, velhos ou furados; e as causas com raízes organizacionais identificadas neste trabalho foram: operário descompromissado, operário desqualificado, falta de padronização da quantidade de massa e o acesso difícil à alguns ambientes da fábrica.

Deste modo, conclui-se que em ordem de prioridade, deve-se eliminar ou minimizar a presença de causas geradas por questões organizacionais, as quais estão imersas no comportamento e na rotina dos funcionários da empresa. Tais decisões devem ser tomadas pelos gestores, visando resultados em um horizonte temporal de longo prazo, pois são mudanças que necessitam de tempo para aceitação, adaptação e aprendizado sobre o "novo ser" da empresa.

Conclui-se, ainda, que os objetivos deste trabalho foram alcançados, e que a metodologia DMAIC mostrou-se eficiente para a sua realização. Espera-se que, com as medidas propostas os desperdícios sejam reduzidos e o nível de qualidade do produto seja elevado. Como principais limitações do estudo estão o acesso às informações devido, sobretudo, ao caráter estratégico destas e a aplicação de outras análises estatísticas e de controle de qualidade que se comportam, nesse sentido, como uma oportunidade de trabalhos futuros.

\section{REFERÊNCIAS}

ASSOCIAÇÃO BRASILEIRA DE NORMAS TÉCNICAS - ABNT.NBR 13207 - Gesso para Construção Civil. Rio de Janeiro, 1994.

BARBOSA, A. A.; A. JÚNIOR, S.; DANTAS, A. C. S.; FERRAZ, A. V. Chemical conversion of a solid body of the composite gypsum/polyhydroxybutyrate in hydroxyapatite/polyhydroxybutyrate. Cerâmica, v. 65, p. 335339, 2019.

BAIRD, K.; HU, K. J.; REEVE, R. The relationships between organizational culture, total quality management practices and operational performance. Journal of Safety Research, v. 39, n. 1, p. 789-914, 2011.

BORNIA, Antonio Cezar. Análise Gerencial de Custos: aplicação em empresas modernas. 3. ed. São Paulo: Atlas, 2010.

CAMPOS, Vicente Falconi. Controle da qualidade total: No estilo japonês. 9. Nova Lima: Falconi, 2014. 286 p.

ESCOBAR, M. A. R.; LIZOTE, S. A.; VERDINELLI, M. A. Relação entre orientação empreendedora, capacidade de inovação e munificência ambiental em agências de viagens. Turismo: Visão e Ação, v. 14, n. 2, p. 269-286, 2012.

CIPRIANO, P. B.; REZENDE, R. T. O.; FERRAZ, A. V. Produção de cerâmica vermelha utilizando argila proveniente da mineração de gipsita e resíduo de gesso. Acta Brasiliensis, v. 3, p. 25, p. 25-29, 2019.

JIRASUKPRASERT, P.; GARZA-REYES, J. A.; KUMAR, V.; LIM, M. K. A Six Sigma and DMAIC application for the reduction of defects in a rubber gloves manufacturing process. International Journal of Lean Six Sigma, $v$. 5, n. 1, p. 2-21, 2014.

JONES, L. S.; LINDERMAN, K. J. Process management, innovation and efficiency performance: The moderating effect of competitive intensity, Business Process Management Journal, v. 20, n. 2, p. 335-358, 2014.

KRÜGER, E. M. Proposta de um modelo de estratégia de operações de serviço para o ensino superior de pós-graduação. Dissertação (Mestrado) - Programa de Pós-Graduação em Engenharia de Produção e Sistemas, Pontifícia Universidade Católica do Paraná, Curitiba, 2013.

KUAN, C. C. C. Research on product reliability improvement by using DMAIC process. Asian Journal on Quality, v. 13, n. 1, p. 67-76, 2012.

LEE, J.; COVELL, M. A strategic approach to overhead management, Strategy \& Leadership, v. 36, n. 2, p. 4046, 2008. 
LIKER, J. K.; MEIER, D. O Modelo Toyota - Manual de Aplicação: um guia prático para a implementação dos 4Ps da Toyota. Porto Alegre: Bookman, 2007.

LIMA FILHO, H. J. B. Tratamento dos Resíduos de Gesso da Construção e da Demolição - RCD para a Produção de Gesso Beta Reciclado. 2010. Dissertação (Mestrado) - Universidade Federal de Pernambuco, Recife, 2010.

MACEDO, M. M. Gestão da produtividade nas empresas. Revista Organização Sistêmica, v. 1, n. 1, p. 110 $119,2012$.

MACHADO, W. R. B.; SANTOS, P. V. S. Mensuração da capacidade do processo de beneficiamento de uva de mesa em um packing house: estudo de caso em uma empresa no Vale do São Francisco. Navus - Revista de Gestão e Tecnologia, [S.I.], v. 10, p. 01-15, 2020.

MAHANTI, R.; ANTONY, J. Six sigma in the Indian software industry: Some observations and results from a pilot survey. TQM Journal, v. 21, n. 6, p. 549-564, 2009.

MANDAL, P. Improving process improvement: executing the analyze and improve phases of DMAIC better. International Journal of Lean Six Sigma, v. 3, n. 3, p. 231- 250, 2012.

MONTGOMERY, D.C.; WOODALL, W.H. An Overview of Six Sigma. International Statistical Review, v. 76, p. 329-346, 2008.

OMACHONU, V. K.; ROSS, J. E. Principles of total quality. 3. ed. Florida: CRC Press LLC, 2004.

PALADINI, E. P. Gestão da qualidade: teoria e prática. São Paulo: Atlas, 2008.

PEINADO, Jurandir; GRAEML, Alexandre R. Administração da produção: operações industriais e de serviços. Curitiba : UnicenP, 2007.

PERES, L.; BENANCHOUR, M.; SANTOS, V. A. Gesso: Produção e Utilização na Construção Civil. Recife: Sebrae, 2008. 119 p.

PIRES, A. R. Sistemas de Gestão da Qualidade: Ambiente, Segurança, Responsabilidade Social, Indústria, Serviços, Administração Pública e Educação. 1. ed. Lisboa. Edições Sílabo, 2012.

PRASHAR, A. Adoption of Six Sigma DMAIC to reduce cost of poor quality. International Journal of Productivity and Performance Management, v. 63, n. 1, p. 103-126, 2014.

SANTOS, A. B.; MARTINS, M. F. Contribuições do Seis Sigma: estudos de caso em multinacionais. Production, v. 20, n. 1, p. 42-53, 2010.

SANTOS, P. V. S. Aplicação do indicador Overall Equipment Effectiveness (OEE): um estudo de caso numa retífica e oficina mecânica. Brazilian Journal of Production Engineering - BJPE, v. 4, p. 1-18, 2018.

SANTOS, P. V. S. A introdução de tecnologias a favor da eficiência em operações logísticas: um estudo de caso no setor de serviços. Navus - Revista de Gestão e Tecnologia, v. 9, n. 3, p. 55-68, 2019.

SANTOS, P. V. S.; FERRAZ, A. V.; SILVA, A. C. G. C. Utilização da ferramenta mapeamento de fluxo de valor (MFV) para identificação de desperdícios no processo produtivo de uma empresa fabricante de gesso.

Revista Produção Online, v. 19, p. 1197-1230, 2019.

SANTOS, P. V. S. Aplicação do overall equipment effectiveness no sistema produtivo de uma vinícola. Navus Revista de Gestão e Tecnologia, v. 10, p. 01-14, 2020.

SANTOS FILHO, V. H.; SANTOS, P. V. S.; OLIVEIRA, K. A. AVALIAÇÃO ESTATÍSTICA DA VARIABILIDADE DE MEDIDA NO PROCESSO PRODUTIVO DE GESSO $\beta$. In: ENCONTRO NACIONAL DE ENGENHARIA DE PRODUÇÃO, 40., 2020, Foz do Iguaçu. Anais [...]. Rio de Janeiro: ABEPRO, 2020. 
SANTOS, P. V. S.; CLEMENTE, T. R. N. PROPOSTA DE INDICADORES PARA AVALIAÇÃO DE DESEMPENHO DE INDÚSTRIAS DO APL DE GESSO DE PERNAMBUCO. In: ENCONTRO NACIONAL DE ENGENHARIA DE PRODUÇÃO, 39., 2019, Santos. Anais [...]. Rio de Janeiro, RJ: ABEPRO, 2019.

SANTOS, P. V. S.; SOUZA, J. A. F. ; SILVA, E. C. ; FERNANDES, C. H. A. . Integração do índice OEE e o método Heijunka: uma análise sobre uma possível relação. Journal of Lean Systems, v. 5, p. 1-25, 2020.

SANTOS, P. V. S.; SILVA, E. C. da. Gestão estratégica da qualidade aplicada à redução de devoluções. Navus Revista de Gestão e Tecnologia, v. 9, n. 4, p. 30-48, 2019.

SHANKAR, R. Process Improvement Using Six Sigma: A DMAIC Guide. Milwaukee: Asq Quality Press, 2009.

SHINOHARA, A. H.; OLIVEIRA, M. A. C. A experiência com gás natural/GLP no polo gesseiro do Araripe, PE.

Cerâmica, São Paulo, v. 60, n. 354, abr. 2014.

SILVA JUNIOR, M. T. Benefícios e dificuldades na adoção de um sistema de gestão da qualidade no Rio Grande do Norte. Dissertação (Mestrado) - Programa de Pós-Graduação Engenharia da Produção, Universidade Federal do Rio Grande do Norte, Rio Grande do Norte, Natal, 2013.

SILVA, J. P. C.; MACHADO, F. O. A Qualidade como estratégia empresarial: um estudo conceitual. INGEPROInovação, Gestão e Produção, v. 3, n. 10, p. 035-046, 2011.

SINDUSGESSO. Sindicato da Indústria do Gesso do Estado de Pernambuco. 2017. Disponível em: http://www.sindusgesso.org.br/. Acesso em: 17 jan. 2021.

SNEE, R. D. Dealing with the Achilles' hell of six sigma initiatives - Project selection is key to success. Quality Progress, v. 34, n. 3, p. 66-72, 2001.

SOKOVIC, M.; PAVLETIC, D.; PIPAN, K.K. Quality Improvement Methodologies - PDCA Cycle, RADAR Matrix DMAIC and DFSS. Journal of Achievements in Materials and Manufacturing Engineering, v. 43, n.1, p. 473-483, 2007.

STAN, L.; MĂRĂSCU, K. V. Techniques to reduce costs sustainable quality in the industrial companies. In: INTERNATIONAL DAAAM BALTIC CONFERENCE "INDUSTRIAL ENGINEERING", 8., Tallin, Estonia. Proceedings [...] Tallinn, Estonia: Innomet, 2012. p. 579-584.

SU, H.; DHANORKAR, S.; LINDERMAN, K. A competitive advantage from implementation timing of ISO management standards. Journal of Operations Management, v. 37, p. 31-44, 2015.

SU, H.; LINDERMAN, K.; SCHROEDER, R.G.; VAN DE VEN, A. A comparative case study of sustaining quality as a competitive advantage. Journal of Operations Management, v. 30, p. 429-445, 2014. 